Revista Iberoamericana, Vol. LXXVII, Núm. 234, Enero-Marzo 2011, 87-110

\title{
EL HUMORISMO GRÁFICO DE MAITENA BURUNDARENA: DE LO LOCAL A LO GLOBAL; DE LOS ESTEREOTIPOS A LA SUBVERSIÓN
}

\author{
POR \\ Gema PÉREZ-SÁNCHeZ \\ University of Miami
}

El número de mujeres del mundo occidental que se han dedicado desde finales de los 60 al humorismo gráfico de tintes feministas y que han logrado alcanzar el éxito editorial y por tanto económico es exiguo. Literalmente se cuentan con los dedos de una mano. De entre las que han publicado con asiduidad destaca, ante todo, la pionera francesa Claire Bretécher, representante de un feminismo audaz pero también autocrítico correspondiente a los años que siguieron al mayo del 68 francés. En EE.UU. sólo encontramos autoras de tiras semanales que plantean pocos o nulos retos al sistema genérico-sexual hegemónico, como la autobiográfica Cathy de Cathy Guisewite (n. 1950) ampliamente sindicada en todos los periódicos nacionales norteamericanos, y alguna que otra tira cómica más alternativa y con más carga feminista como la absurdista Sylvia (posteriormente recogida en un libro titulado Tales from Planet Sylvia [1990]), de Nicole Hollander (n. 1939). En los espacios abiertos por la prensa alternativa -léase progresista, de tiradas y distribución limitadas-destaca la multifacética Alison Bechdel quien, a pesar de contar desde 1986 con numerosas lectoras lesbianas y feministas que siguen con avidez y fidelidad su serie Dykes to Watch Out for, ha tenido que esperar hasta 2006 para ser reconocida por un público mainstream. Dicho reconocimiento le ha llegado de la mano del éxito editorial de su impresionante memoria gráfica, Fun Home: A Family Tragicomic (2006), la cual se mantuvo en las listas de los bestsellers del New York Times y de Los Angeles Times durante varias semanas. Si pasamos al mundo hispanohablante, el panorama es aún más deprimente. Como ya demostré en otra ocasión en el contexto de la España contemporánea (Pérez-Sánchez 162-71), las opciones disponibles para las historietistas españolas feministas han sido mínimas. Sólo el espacio abierto por la revista Madriz, subvencionada por el Ayuntamiento de Madrid, permitió brevemente (de 1984 a 1987) que narradoras gráficas del talento de Ana Miralles, Ana Juan, Victoria Martos, Nines y la tristemente fallecida Asun Balzola encontraran un medio de expresión. Con la desaparición de esta revista y el poco éxito de su continuadora, Medios Revueltos (también bajo la dirección del visionario Felipe Hernández Cava, pero sin el apoyo económico del dinero público), las oportunidades de 
publicación para las mujeres historietistas españolas se vieron drásticamente limitadas, a no ser que éstas se prestaran a amoldarse a los dictados del mercado editorial del cómic tradicional, es decir, ilustrando guiones de temática machista y de explotación de la sexualidad femenina, como ha sido el caso de Ana Miralles. ${ }^{1}$ Esta escasez de producción femenina a finales del milenio sorprende especialmente porque, como indica Javier Coma, "[e]ntre el crepúsculo de los años veinte y el ecuador de los cincuenta proliferaron las obras femeninas en la Prensa norteamericana ...," al mismo tiempo que España vio florecer la obra de varias artistas de la narrativa gráfica, incluso bajo el franquismo (322). Escribiendo en 1988, Coma admite que el éxito editorial que disfrutaron las series creadas por mujeres en las primeras décadas del siglo xx contrasta "con el escaso interés que actualmente demuestran las editoriales españolas por creadoras de probado talento" (322). ${ }^{2}$ Ante un panorama tan desolador para las mujeres historietistas de la última década del siglo xx y la primera del xxi, es refrescante y digno de estudio el éxito arrollador de la argentina Maitena Burundarena quien, para la fecha (1999) de su descubrimiento en España y el resto del mundo, gracias a que su sus chistes empiezan a ser publicados en el periódico español El País, ya había alcanzando notoriedad en la Argentina con su tira semanal, Mujeres alteradas (publicada en la revista femenina Para Ti), fama que se consolidó a partir de 1998 con la tira Superadas publicada en el diario conservador argentino de mayor tirada, La Nación.

La sexta de siete hermanos, Maitena Burundarena nació en Buenos Aires, Argentina, en 1962 en el seno de una familia católica conservadora. Su padre desempeñó un cargo político importante como ministro de Educación del Proceso durante la dictadura militar (Moreno 243) y su madre era hija de inmigrantes polacos de origen humilde quienes, sin embargo, animaron a su hija a estudiar arquitectura. ${ }^{3}$ Tras quedar embarazada a los

1 El contexto español que proporciono en este ensayo sobre la argentina Maitena Burundarena no es gratuito ni constituye un gesto de apropiación cultural, sino que me parece fundamental para entender el ambiente en el que la obra de Maitena salta al estrellato mundial. Es importante recordar que por esos mismos años ochenta de la famosa movida madrileña cuando estas dibujantes españolas se abrían camino, Maitena publicaba algunos de sus cómics “serios” en la legendaria revista Makoki, al mismo tiempo que en su país se daba a conocer en el circuito de los cómics underground eróticos publicando en Sex Humor y Fierro.

2 Coma provee una importante lista de mujeres guionistas y artistas de cómics tanto en España como en el extranjero desde finales de los años 20 hasta los 80 del siglo xx, aunque, significativamente, no incluye a ninguna latinoamericana (Coma 322).

3 En una entrevista reciente, Maitena reconoce que, aunque tuvo una mala relación con su madre, la mayoría de los problemas de nervios que ésta sufrió se derivan de la situación machista en la que se vio atrapada esta madre con estudios y ambiciones zafadas por un marido ultra católico y conservador: "Ella no era muy católica y era arquitecta. Dejó una carrera que le costó mucho hacer, porque no era una chica de clase social alta. Era hija de polacos inmigrantes, y fue a la universidad en una época en que muchas de las mujeres no iban, y menos las hijas de sastres como ella. Y allí conoció a mi padre. Creo que primero fue para mi madre un gran enamoramiento, pero después la sumió en una vida terrible. Mi padre le hizo un hijo atrás del otro, y mi madre terminó mal. Con rencor y con sufrimiento y con crisis nerviosas [...]

Revista Iberoamericana, Vol. LXXVII, Núm. 234, Enero-Marzo 2011, $87-110$
ISSN 2154-4794 (Electrónico) 
17 años, Maitena abandona sus estudios antes de acabar la escuela secundaria (Tusquets 18, 22) y "[c]omo autodidacta, fue encontrando su propio estilo trabajando mucho y mirando mucho a grandes como Quino, Fontanarrosa, Hugo Pratt, entre otros" (Malamud 25). Comenzó su carrera como historietista durante el boom de los comics españoles de los años 80, publicando series eróticas en revistas de la movida madrileña de la talla de Makoki y en publicaciones underground argentinas como Sex Humor, Fierro, Humor y Cerdos \& Peces (Burundarena, "Biografía” par. 4). Trabajó para varias revistas y periódicos e incluso ilustró libros de texto y manuales. Se desempeñó brevemente como guionista de televisión e incluso llegó a regentar un restaurante, un bar y un kiosko de periódicos (Burundarena, "Biografía” par. 4). Tras su éxito inicial en la Argentina, la serie Mujeres alteradas se publicó en numerosos periódicos latinoamericanos y europeos, como la Stampa (Turín), El País (Montevideo), El Nacional (Caracas) y El Mercurio (Santiago de Chile)(Tompkins 21). En 2005, los cinco volúmenes de la colección Mujeres alteradas fueron recopilados en un voluminoso ejemplar de grandes ventas. Su siguiente serie, Superadas, recibe su título del adjetivo que despectivamente usaba el padre de Maitena para referirse "a las mujeres que se divorciaban y se volvían a casar, tomaban anticonceptivos o se analizaban, o todo eso junto" (Burundarena, Todas las superadas 5). Su serie más reciente, Curvas peligrosas, de la cual ha publicado dos volúmenes, ha sido recibida con igual éxito de ventas. Las cifras de ventas sólo de las versiones en castellano de todos sus libros ascienden a más del millón y medio de ejemplares (Burundarena, “Biografía” par. 3). Su “marca," como la propia página web de Maitena la denomina (Burundarena, "Biografía” par. 13), se ha expandido considerablemente e incluye calendarios de mesa, agendas y otros productos, llegando a convertir el nombremarca "Maitena" en una línea comercial lucrativa.

Las españolas Asun Balzola, Ana Juan y Ana Miralles, entre otras pocas en los años 80, habían abierto una brecha en la fortaleza aparentemente inexpugnable del mundo eminentemente masculino del cómic, pero se vieron inevitablemente frenadas en su progreso por el bastión de los constreñimientos machistas del mercado editorial y el público habitual de los cómics. ${ }^{4}$ En contraste, Maitena, representante de una nueva

[C]uando supo que estaba embarazada de mí, se pegó cabezazos contra la pared. Su primera reacción fue ésta. Y escondió el embarazo hasta los seis meses. Le daba vergüenza que las vecinas le dijeran: ‘¡Otra vez!’Y después todavía tuvo dos hijos más” (Tusquets 25).

4 En España, como en la Argentina y como en el resto del mundo occidental, el problema al que se han enfrentado las dibujantes de cómics es el machismo típico de este campo, como indica Javier Coma: "La hegemonía masculina estimula muy poco el ascenso de la mujer a los primeros planos de la vida colectiva y así ocurre en el sector profesional de los comics ("En manos femeninas" 321). Este machismo, que tiene consecuencias estéticas y profesionales para las mujeres dibujantes, se ve reforzado por los constreñimientos del mercado capitalista, el cual exige que los y las dibujantes de cómics respondan a los gustos de los lectores, la mayoría de los cuales son hombres, para poder superar las cuotas de ventas. Una de las pioneras españolas del cómic, Marika (Mari Carmen Vila) confirma el machismo

ISSN 0034-9631 (Impreso) 
generación de dibujantes (y parte de la llamada Generación X) influidas por el feminismo y que se han beneficiado de los logros políticos y sociales de este movimiento, alcanza mayor éxito editorial y de público, específicamente en España y en el resto de Europa, que sus antecesoras españolas y argentinas por varios motivos dignos de explorar. Ante todo, a Maitena se la considera desde varios campos como la continuadora del legado del gran Quino (Joaquín Salvador Lavado) y su celebérrimo personaje Mafalda (Fernández L’Hoeste, “Más allá” 15), conexión que el mismo Quino facilita al darle el espaldarazo de prologar la primera edición completa de las Mujeres alteradas. Sin duda, el humor crítico distintivamente argentino de Mafalda le ha creado a Maitena la predisposición positiva de un público hispanohablante internacional que buscaba una continuación al humor inteligente y cáustico de Quino, pero que también quería superar el universo infantil de Mafalda para tratar temas más adultos que ni se mencionaban en dicha tira cómica, de humor más “blanco” y más enfocado específicamente en criticar los eventos políticos mundiales y locales. Maitena es beneficiaria, además, del camino que ya habían abierto tanto dibujantes argentinas de la talla de María Alcobre y Patrica Breccia (Tompkins 41) como españolas del calibre de Balzola, Juan, Martos y Miralles (recordemos que fue la publicación de la obra de Maitena en España lo que le facilitó el éxito internacional y el salto de ser un fenómeno local a uno global, aunque no creo que Maitena conociera directamente la obra de ninguna de estas artistas españolas). Añádase a esto el que, en Europa, a Maitena le allanara el camino de la tira cómica feminista la

\begin{abstract}
del medio: "Es un medio que se encuentra marcado por códigos fuertemente masculinos, ya que todos sus elementos -industria, autores y el más importante, el público- están formados tradicionalmente por varones. Si sumamos a esto el hecho de que el lector fiel es escaso comprenderemos que los temas rentables estén limitados a su medida. [...] Su calidad de profesión liberal mal pagada y peor atendida marca unas connotaciones de dureza, individualidad y agresividad. En ella no está seriamente valorados ni siquiera los hombres, cuando menos las mujeres” (323). Al margen del hecho de que Marika no puede concebir que existan mujeres que puedan ser duras, individualistas y agresivas, cayendo así en la típica falacia esencialista que insiste en la pasividad para la mujer y la agresividad para el hombre, es obvio para cualquiera familiarizado con el mundo de los cómics para adultos en Europa y las Américas que la gama de temas y representaciones genérico-sexuales disponibles en el medio está limitada a los gustos tradicionales de un cierto tipo de hombres heterosexuales y blancos. Así, como ha indicado Coma, el trabajo de las mujeres ilustradoras de cómics suele caer "en el vasallaje a los goces sexistas del varón común” ("En manos femeninas” 321). Dada la escasez de oportunidades de publicar en revistas que no fueran esclavas del mercado editorial -como he demostrado en otro momento que lo fuera la revista Madriz en España (Pérez-Sánchez 143-86)- las pocas españolas que he estudiado en otra ocasión se ven abocadas a seguir tres posibles rutas profesionales: Ana Juan termina dedicándose exclusivamente a la pintura y la ilustración, abandonando el mundo de los cómics; Asun Balzola eventualmente abandona completamente el mundo del cómic y la ilustración para adultos para dedicarse al medio puramente verbal de la narrativa y la autobiografía y a ilustrar libros para niños; y Ana Miralles, la única del grupo que todavía sigue ganándose la vida (y bastante bien, por cierto) con su trabajo como dibujante de cómics, participa en el mercado capitalista de pleno viéndose forzada a ilustrar los guiones mayormente machistas y racistas que le ofrecen.
\end{abstract}

Revista Iberoamericana, Vol. LXXVII, Núm. 234, Enero-Marzo 2011, 87-110
ISSN 2154-4794 (Electrónico) 
pionera Bretécher. Y, finalmente, su éxito coincide con la creciente presencia y prestigio no sólo en Europa, sino también en los países de habla hispana, especialmente España, de la obra feminista lesbiana de Bechdel, compañera de generación de Maitena. Es decir, el fenómeno "Maitena" no se produce en un vacío, sino dentro de una comunidad de precursoras y compañeras de viaje que se han abierto camino por terrenos antes intransitables.

En este ensayo me interesa, por tanto, apuntar que en Maitena-tanto en su obra como en el fenómeno en el que se ha convertido su nombre-marca- se conjugan una serie de coordenadas históricas, de mercado y de cambios de expectativas en el público ${ }^{5}$ que le ayudan a tener un amplio y complejo impacto político en cuanto a la representación de las relaciones entre los sexos, al mismo tiempo que es capaz de lanzar críticas -unas más veladas que otras-contra el racismo, el consumismo desenfrenado, la lesbofobia y otros prejuicios dominantes en el mundo de la clase media blanca occidental. Sus predecesoras no lograron crear tal impacto político ni lograron semejante éxito de público, y esto a pesar de las indudables contradicciones y ambigüedades que el discurso genéricosexual de Maitena manifiesta. Sin disminuir la importancia del contexto argentino de la producción temprana de Maitena -el cual ya ha delineado magistralmente Cynthia Tompkins-me interesa considerar su obra dentro del contexto global de estas humoristas gráficas y trabajadoras del cómic de España, Francia y los EE.UU. que abrieron brecha. Quisiera apuntar los aspectos más interesantes que, desde mi perspectiva, se desprenden de un análisis de conjunto de la obra de Maitena, a saber: las tensiones entre lo local y lo global y entre la tradición humorística argentina y la nueva tradición creada por las humoristas globales que ya he mencionado.

En cuanto a las tensiones entre lo local y lo global, es indudable que Maitena se ha convertido en una figura de impacto mundial que trasciende fronteras geográficas, de manera semejante a como lo hiciera en los 60 y 70 Bretécher $^{6}$ o Bechdel más recientemente. La obra de Maitena se ha publicado en doce lenguas, entre ellas el inglés, el italiano, el francés, el portugués, el catalán, el alemán y el neerlandés. Ha aparecido publicada en los rotativos de mayor prestigio de Europa y Latinoamérica y sus tiras cómicas las leen en culturas tan dispares como la islandesa, la griega, la alemana, la holandesa y la

5 Con ocasión de reseñar la traducción al inglés de la obra de Maitena, Larry Rohter indicaba en The New York Times que, "Maitena's admirers regard her as a cultural phenomenon that simply could have not existed 15 years ago. Louise Mereles Gras, editorial director of the Mexican edition of Marie-Claire magazine, talks about 'a generational transition' of mores and values occurring throughout the region that finds expression in Maitena’s work” (par. 4). Igualmente, Héctor D. Fernández L’Hoeste ha indicado que "Latin American comics have a new audience, the many women eager to recognize themselves in a cultural product concocted by one of their own" ("Beyond" 346).

6 Ana Merino, sagazmente, ha indicado que la admiración de Maitena "por la obra de la francesa Claire Bretecher [sic] ha sido clave en el aprendizaje de una temática que parodia lo que podría denominarse una feminidad corrosiva” ("Maitena” 178).

ISSN 0034-9631 (Impreso) 
coreana (Burundarena, “Biografía” par. 3). En una de las numerosas entrevistas que a lo largo de los años ha concedido a la prensa -en las cuales Maitena siempre demuestra un sentido del humor punzante y una notoria ambivalencia ante el feminismo ${ }^{7}-$ a la pregunta de si se sentía una humorista global, la argentina responde: "Bueno, las mujeres no somos todas iguales pero nos pasan las mismas cosas” (Krmpotic 77). Su respuesta sugiere que es consciente de que las semejanzas en el tipo de opresión que sufren las mujeres en el mundo no garantizan que haya similitudes en las respuestas culturales a dichas experiencias. A su vez, esta contestación revela simultáneamente un deseo de representar de manera crítica las experiencias de opresión comunes a todas las mujeres, al mismo tiempo que de respetar las diferencias culturales de cada contexto nacional. Sin embargo, a pesar de este impacto global de Maitena, la humorista considera que cometió un grave error profesional cuando, antes de su gran éxito internacional, buscando precisamente dicho salto global, pretendió crear cómics específicamente para el mercado europeo, abandonando sus raíces argentinas:

Por primera vez en mi vida intenté hacer algo para vender afuera. Y nunca hay que pensar en esto; es una manera muy equivocada de trabajar. Habían tenido éxito mis historietas como eran: historietas de esa chica latinoamericana [Coramina], con esos personajes. Cuando trato de hacer una historieta ambientada en París, y hago una historieta ambientada en los metros de París, no pasa nada. Sí, se vende a dos o tres revistas, pero no pasa lo que yo pensé que iba a pasar, y era un montón de trabajo. (Tusquets 44-45)

Significativamente, entonces, según Maitena, lo que se fetichiza en el mercado global es la especificidad latinoamericana de su obra. Y sin embargo, como indicaré en breve, la ironía es que, para lograr su éxito mundial, el dialecto argentino de sus personajes habrá de ser “traducido” al dialecto español peninsular.

En cuanto a la tradición de narrativa gráfica en la que se inserta Maitena, se la ha agrupado con otras historietistas argentinas de importancia, como Alcobre y Breccia (Tompkins 41), así como se la ha asociado a los grandes nombres de la narrativa gráfica argentina por antonomasia: Fontanarrosa, el uruguayo Alberto Breccia, o el italiano afincado en argentina, Hugo Pratt. Pablo de Santis injerta a Maitena dentro de una tradición costumbrista eminentemente argentina (par. 2). Para este crítico,

El costumbrismo tiene una larga historia en el humor gráfico argentino. Su meta es que el lector se reconozca en la página como si se tratara de un espejo. Maitena consigue ese efecto pero se detiene en ese instante: al dejar que el lector complete la situación y

\footnotetext{
Sin embargo, Maitena siempre repite que: "yo creo que todas las mujeres, cuando nos preguntan ' ¿sos feminista?, tenemos que responder 'sí', porque el feminismo, con todos los cambios que ha generado en la vida de las mujeres, es sin duda el movimiento político más importante del último siglo. Yo siempre les digo a las chicas de veinte años que, si no fuera por el feminismo, estaban planchando" (Tusquets 63).

$\begin{array}{lllll}\text { Revista Iberoamericana, Vol. LXXVII, Núm. 234, } & \text { Enero-Marzo 2011, } 87-110 \\ \text { ISSN 0034-9631 (Impreso) }\end{array}$
} 
establezca relaciones entre los distintos cuadros, la dibujante se despega de todas las formas de identificación obvia que busca hoy -en teatro, libros y televisión- el humor destinado a las mujeres. (par. 2)

Por su parte, Tompkins compara "[l]a delicadez del trazo, lo etéreo de la elegancia de los dibujos de Mujeres [alteradas]" con el "estilo de artistas gráficos tales como B. Smaller [del New Yorker]" mientras que argumenta que las ilustraciones de Superadas "se asemejan a las de la humorista francesa Claire Bretécher, pero no pierden las características del telúrico grotesco criollo" (56). Por tanto, hay acuerdo entre los críticos argentinos de que el estilo gráfico de Maitena se inserta simultáneamente en una tradición costumbrista argentina a la par que dialoga y se ve influida por los estilos europeos en boga desde los 70 en adelante. De nuevo se perciben aquí las tensiones entre la especificidad de lo local y la inserción en un mercado y una cultural occidental globalizadas. ${ }^{8}$

Dentro del ilustre pedigrí de la tradición narrativa gráfica argentina en la que se inserta la obra de Maitena, se la ha reconocido ante todo como la heredera directa del humor del gigante de la tira cómica Quino, cuya famosa Mafalda es, sin lugar a duda, la historieta de mayor fama jamás publicada en castellano (Fernández L’Hoeste, “Más allá” 15). Sin embargo, mientras que Mafalda se distribuía en el mundo hispano-hablante en su dialecto original argentino, cuando la obra de Maitena se empieza a publicar en el suplemento semanal del períodico español El País en 1999, fue "traducida" del dialecto argentino al español ("chaqueta" por "remera", "tía” por "mina”, "tú" por "vos", además de sustituir las formas verbales en la segunda persona del singular típicas del dialecto argentino, "querés, "tomás," por las convencionales "quieres," "tomas," etc.). En la biografía que la propia Maitena escribe para su página oficial en la web, la historietista marca esta traducción del dialecto argentino al español como el comienzo de su internacionalización y de su éxito de ventas ("Biografía” par. 7). Las razones de mercadeo tras esta decisión de "traducir" la obra de Maitena son obvias (más alcance en el mercado español y de otros países hispanohablantes no del Cono Sur por medio de la elisión de las marcas de lo autóctono argentino). No obstante, la práctica sigue siendo sorprendente, puesto que el dialecto argentino es ampliamente comprendido en el mundo hispano. ${ }^{9}$ De hecho, se podría asegurar que la popularidad de la Mafalda de Quino se debe, en gran parte, a la fascinación que ejercían en muchos hispanohablantes las cadencias distintivas y la jerga lunfarda de esta querida historieta. Por lo tanto, se

8 Si el lector desea ampliar sus lecturas sobre el humorismo gráfico y los cómics en la Argentina, le recomiendo el excelente capítulo sexto, “Argentina: la mirada fantástica”, del libro de Merino.

9 Resulta gracioso que esta operación quirúrgica de despojamiento de toda marca de lo autóctono argentina en la obra de Maitena no haya podido borrar del código gráfico de su obra gestos típicos argentinos, como el elocuente gesto con una mano que suele acompañar al "che" verbal. En estos casos, se crean momentos de verdadera disonancia cognitiva entre lo que dice un personaje y los gestos del dibujo: traduttore, traditore.

ISSN 0034-9631 (Impreso) 
podría haber esperado que las tiras de Maitena se hubieran recibido bien en su "argentino" original. Se me ocurren varias hipótesis para explicar la razón de dicha traducción. Una de ellas es la obvia que apunté antes: la posibilidad de que la adaptación de los cómics de Maitena al dialecto español peninsular surja de un deseo editorial de borrar las diferencias locales y lograr que el trabajo de Maitena se venda al mayor numero de lectores posibles. Y, sin embargo, cabe preguntarse por qué no haberlo adaptado a un dialecto más neutral y reconocido, como podrían ser el venezolano o el colombiano y no al español peninsular -uno de los más característicos y diferentes, junto con el argentino, de todo el mundo hispanohablante--. Desde este punto de vista, dicha traducción despide un leve tufillo neocolonialista español (semejante a la toma por parte de Iberia de las Aerolíneas Argentinas en los 90, o la infiltración de la compañía Telefónica española en todo el Cono Sur). Esta “españolización” de Maitena, hasta el punto de que muchos lectores y no pocos críticos la identifican como española o argentina afincada en España (véase, por ejemplo, Cipolloni, pero nótese que Maitena reside en Uruguay), sugiere la importancia de estudiar su obra no sólo en el contexto exclusivamente argentino, sino también en el contexto de las artistas gráficas españolas que mencioné al principio del ensayo y de las otras precursoras o coetáneas internacionales como Bretécher, Bechdel, también mencionadas.

Permítaseme un pequeño desvío para traer a colación dos citas que ya he usado en otro contexto (Pérez-Sánchez 148-49) pero que me parecen cruciales para recordarnos por qué es importante analizar los cómics en general y la tira cómica en particular. Miguel Ángel Gallo insiste en que:

la historieta es un excelente vehículo de ideologías, y por tanto puede ayudar al reforzamiento del orden imperante, o al contrario, puede ser un importante medio de politización.... [E]s un reflejo de la sociedad en que se gesta, y corresponde en mucho a los momentos históricos concretos de los que resulta. Es por ello, no sólo producto de la estructura económica, sino que resume también la lucha de clases, las coyunturas políticas, la ideología, las modas estéticas en boga, la relación con los medios de comunicación, con el cine y la literatura, etc. $(78-79,85)$

En este sentido, me parece fundamental contribuir al exiguo número de estudios académicos sobre la obra de Maitena, ${ }^{10}$ una obra que, en principio, pudiera parecer

${ }^{10}$ Sorprende la poca atención que la obra de esta prolífica argentina ha despertado en el mundo académico del hispanismo y la dificultad que encuentra el estudioso para acceder a este exiguo corpus de erudición. Entre los estudios más destacados se encuentran los ya mencionados de Tompkins y Cipolloni (aunque el de éste último se trate de una simple reseña sobre la reciente publicación en Italia de varias obras del feminismo español de la nueva ola); los dos ensayos de Héctor D. Fernández L’Hoeste, "Beyond Just Gender: On the World of Maitena Burundarena,” y la versión ligeramente cambiada del mismo en castellano, "Más allá del género: acerca del mundo de Maitena Burundarena;” la importante nota para la

$\begin{array}{lllll}\text { ISSN 0034-9631 (Impreso) } & \text { ISSN 2154-4794 (Electrónico) }\end{array}$ 
frívola o de poco interés -puesto que una lectura superficial tiende a dividir a los lectores adversos en dos campos, los que creen que es de un feminismo rábido y trasnochado y los que creen que no es lo suficientemente feminista y que repite estereotipos manidos sobre la guerra de los sexos- pero que analizada en conjunto deviene un corpus complejo y subversivo si se lo contextualiza apropiadamente. ${ }^{11}$ Conviene recordar aquí también las palabras de Ana Merino, en su excelente libro El cómic hispánico, donde demuestra con contundencia que:

El cómic pertenece a la cultura industrial y, como tal, construye relatos modernos, aunque su capacidad legitimadora está en tensión con el discurso letrado. Los cómics anuncian la postmodernidad sin dejar de ser modernos, surgen en un espacio genuinamente moderno pero, al ser rechazados por la cultura letrada, se vuelven marginales y desde allí construyen sus propios relatos... Los cómics son un tipo de relato gráfico que legitima un saber no desde una dimensión política o filosófica propiamente dicha, sino desde una dimensión ideológica de representación masiva y popular. Esta capacidad de legitimación de un saber masivo y popular es lo que le hace ser tan moderno. (11)

Es precisamente “un saber masivo y popular" sobre las experiencias de las mujeres -las cuales se han visto tradicionalmente silenciadas y sometidas a roles pasivos no sólo en la vida diaria sino también en su representación gráfica- lo que Maitena reivindica en su variada representación de la mujer occidental contemporánea de clase media. Como la propia Merino acertadamente arguye, la primera obra de éxito de Maitena, Mujeres

revista Leer que Ana Merino realizara en el 2007 (“Maitena y las transformaciones de las mujeres”); y dos tesis de maestría, una de Michele Abreu Vivas para la Pontificia Universidade Católica do Rio de Janeiro, “'Literatura Mulherzinha’: a construção de feminilidades nas tirinhas da série Mulheres Alteradas de Maitena,” de poco interés para el presente estudio por tratarse de un análisis estructuralista del lenguaje usado en las viñetas de Maitena, y otra de Daiany Ferreira Dantas para la Universidade Federal de Pernambuco, titulada "Sexo, Mentiras e HG: Representação e auto-representação das mulheres nos quadrinhos," también de poco interés aunque de indudable valor como muestra de que Maitena cuenta con un ávido público lector en Brasil, especialmente entre las jóvenes universitarias. Se han escrito, sin embargo, ríos de tinta sobre Maitena en los periódicos y revistas de consumo habitual entre el público general. Es especialmente notoria la superabundancia de entrevistas con la humorista, siendo la más notable y completa la extensa conversación que publicó en forma de libro en 2005 la escritora catalana Esther Tusquets, dueña por muchos años de la prestigiosa Editorial Lumen y editora, por tanto, de gran parte de la obra de Maitena en España (así como de la de Quino). Se necesitan todavía estudios más complejos y extensos que incluyan los detalles de producción, venta y distribución de la obra de Maitena, así como de su recepción internacional. Mi ensayo es sólo un modesto acercamiento preliminar que no puede más que apuntar algunas líneas de interpretación sobre la extensa obra de la humorista argentina.

11 María Moreno resume útilmente la actitud de muchos lectores de Maitena: "Para muchos, las mujeres alteradas de Maitena son demasiado heterosexuales, demasiado pendientes del amor o demasiado obedientes a los mandatos del fascismo del cuerpo o demasiado saludables... Pero también se podría leer a Maitena entre líneas... O como una burla a los mandatos que siguen funcionando a pesar de los imperativos de la conciencia crítica...” (245).

Revista Iberoamericana, Vol. LXXVII, Núm. 234, Enero-Marzo 2011, $87-110$
ISSN 0034-9631 (Impreso) 
alteradas, funcionó porque "[e]ran páginas de historietas cerradas donde las mujeres constituían el eje temático. No existía una protagonista definida que fuese la heroína de ese universo dibujado" ("Maitena” 178), al contrario de la Mafalda de Quino, añadiría yo. Y creo que esto es significativo porque demuestra que Maitena apunta a una nueva sensibilidad que la lleva a hacer de los temas genérico-sexuales los protagonistas de su tira, en vez de subrayar a una protagonista que ayude en el proceso de identificación emocional (cathexis o carga, en téminos psicoanalíticos). Maitena misma ha indicado que cuando el editor Daniel Pliner la contrató por primera vez para que diseñara una tira cómica con un personaje femenino para la revista Para ti, lo que luego constituiría Mujeres alteradas, lo primero que Maitena decidió fue:

no poner un personaje fijo porque en ese caso siempre termina siendo tu alter ego y desnudándote a vos. Además me parecía que si quería hablar con las mujeres tenía que poder incluir a las flacas, las gordas, las que tienen guita, las que no tienen, las que están al pedo y las que se desloman, la esposa, la amante y la secretaria. Y entonces me pareció más fácil hablar de temas que de personas. (Moreno 242)

En cierta forma, por tanto, a través de darle protagonismo a los temas y no a los personajes, Maitena invita a sus lectores a realizar una reflexión intelectual en clave de humor sobre los logros o falta de logros de la mujer occidental de clase media en una época de llamado "posfeminismo". Merino indica, en esta línea, que "[e]l humor [de Mujeres alteradas] se fraguaba desde la articulación irónica de los estereotipos femeninos. Se centraba en el ámbito de las mujeres de la clase media rioplatnense de la época, pero tratando de abrir el abanico a una feminidad abstracta impregnada de modernidad" ("Maitena” 178). Y me parece crucial subrayar, con Marta Dillon, que Maitena es siempre consciente de que "las mujeres que ella retrata con sus nimios problemas cotidianos no son todas, sencillamente hay coordenadas de clase. $\mathrm{Y}$ en esas coordenadas se aloja uno de sus temas favoritos para la caricatura: el consumo" (Dillon par. 17), entre muchos otros temas de crítica y escarnio. Más significativo aún para entender la importancia de la intervención de Maitena en el panorama internacional de mujeres en el humorismo gráfico es, como propone Merino, que:

al introducir a la mujer como elemento humorístico y redefinir su multiplicidad desde sus variables afectivas, culturales, sociales y económicas, cambiaba los registros de una audiencia acostumbrada a temas predominantemente masculinos en la sección gráfica de la prensa. Curiosamente el tema de lo femenino comienza a replantearse a mediados de los 90 como el eje de una nueva expresividad consumista en la producción mediática anglosajona. Surge la llamada chick lit... representando un mundo lleno de lugares comunes. Son mujeres subyugadas por la moda que aspiran a encontrar al hombre de su vida.

Revista Iberoamericana, Vol. LXXVII, Núm. 234, Enero-Marzo 2011,
ISSN 2154-110 


\begin{abstract}
Maitena da la vuelta a esos discursos de cuento de hadas, princesas y príncipes azules, y ofrece una visión muy sarcástica de la cotidianeidad de una clase media femenina llena de contradicciones. ("Maitena” 178-79)
\end{abstract}

Sus lectores se componen, por tanto, fundamentalmente de mujeres heterosexuales hispanas de clase media y media-alta de todas las edades. Pero no hay que olvidar que recientemente, como han documentado algunos estudiosos, "her characters are rapidly gaining popularity among the U.S. Latino college crowd” (Fernández L'Hoeste, “Beyond Just Gender” 346). No debe sorprender el que algunos hombres también disfruten de la obra de Maitena, tal vez porque uno de sus temas dominantes es el tira y afloja en las relaciones heterosexuales en las que ambos sexos son culpables de juegos emocionales y de poder. Maitena no siempre toma el lado de las mujeres en las disputas que presenta, sino que a menudo apunta a la manera en que algunas mujeres perpetúan comportamientos machistas en los hombres y los niños (véase fig. 1). De esta manera, Maitena propone un análisis complejo de las diferencias en los comportamientos genéricosexuales y se niega a seguir culpando de la perpetuación del machismo, a estas alturas de la historia, exclusivamente a los hombres (véase fig. 2).

Los escasos estudios críticos sobre Maitena presentan fundamentalmente dos tendencias argumentativas. Por un lado se encuentran aquellos críticos que lamentan en la obra de Maitena la falta de conciencia de la opresión de clase y un racismo tácito, además de apuntar la manera en que la mayoría de sus tiras cómicas reinscriben estereotipos de género y clase social(Fernández L’Hoeste). Por otro lado, contamos con aquéllos

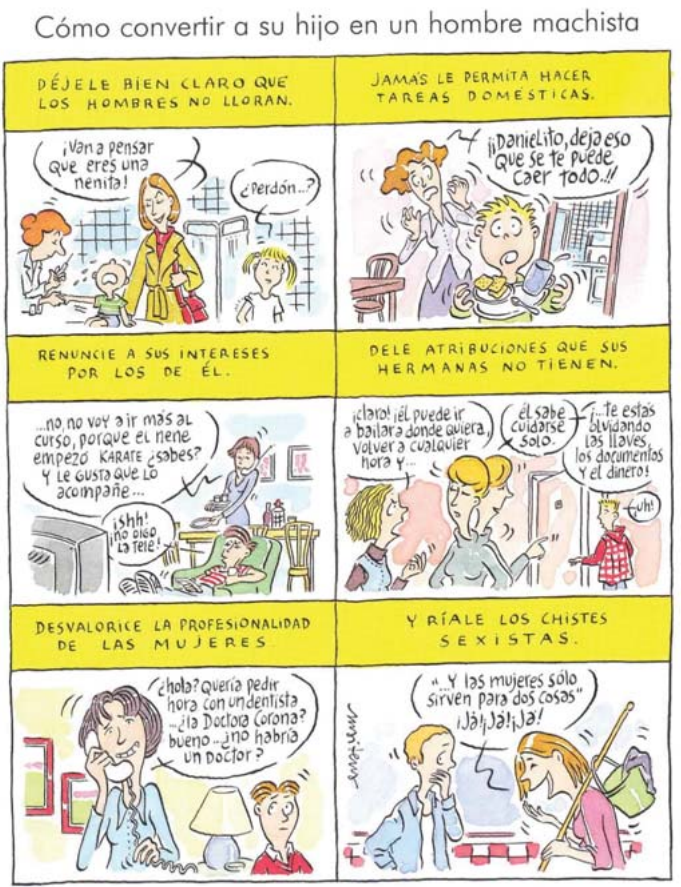

Fig. 1 Maitena Burundarena, “Cómo convertir a su hijo en un hombre machista”. Todas las mujeres alteradas. $2^{\mathrm{a}}$ ed. (Barcelona: DeBolsillo/Random House Mondadori, 2007; 128) que celebran su feminismo, al mismo tiempo que intentan acallar o dar menos importancia a los momentos en los que Maitena cae en clichés manidos sobre la "lucha de los sexos" (Cipolloni, Tompkins,

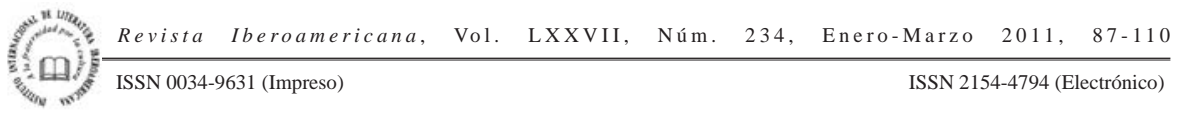


Merino). Un representante de la primera tendencia es el crítico Héctor Fernández L’Hoeste quien, con cierta carga de razón, se lamenta de que, "en materia de clase y raza, tal como Mafalda, Maitena no esgrime una perspectiva tan incluyente como se supondría a primera vista” ("Más allá” 15). Mientras que esto puede ser en parte cierto, me parece sospechoso que, al contrario de los análisis que se suelen hacer de la obra gráfica de humoristas hombres, a Maitena se la exija ser políticamente correcta en toda la gama de marcas identitarias: raza, género, clase social y orientación sexual (Tompkins, por ejemplo, apunta la falta de representación de lesbianas en Mujeres alteradas [22]). Si a todos los hombres creadores de cómics los críticos les exigieran que realizaran representaciones responsables de género, raza, etc. ¡no quedaría títere sin cabeza! pues la mayoría de la producción hegemónica masculina en cómics y humorismo gráfico es sexista, racista y homófoba. Dicho de otra manera, este crítico está sometiendo la obra de Maitena a un escrutinio y unas exigencias que sin duda no reciben los colegas hombres de Maitena. No sorprende en absoluto que la misma Maitena sea consciente de este tipo sutil de machismo. Así, a la pregunta de Esther Tusquets de si le supuso una desventaja

¿Seguro que las mujeres no somos machistas?

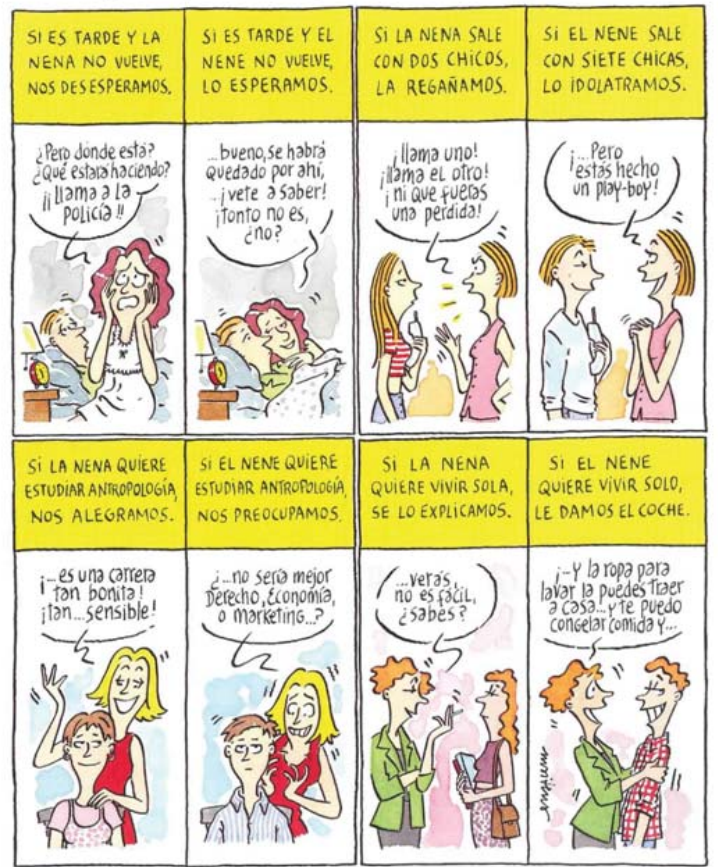
profesionalmente ser mujer, a pesar de que de primeras Maitena indica que no sufrió ningún tipo de desventaja, posteriormente aclara que "[l]o que sí es verdad es que hay muchos humoristas hombres muy malos publicando en un montón de medios, $\mathrm{y}$, cuando una mujer publica en medios importantes, en general es buena” (Tuquets 49). Es decir, una manifestación típica del sexismo, como bien se sabe, es que a la mujer profesional se le exige que sea mucho más competente que un hombre en su mismo puesto. En otras palabras, a la mujer no se le permite el lujo de la mediocridad -lujo del que muchos hombres disfrutan-.

Fig. 2. Maitena Burundarena, "¿Seguro que las mujeres no somos machistas?” Todas las mujere alteradas. $2^{\mathrm{a}}$ ed. (Barcelona: DeBolsillo/Random House Mondadori, 2007; 97).

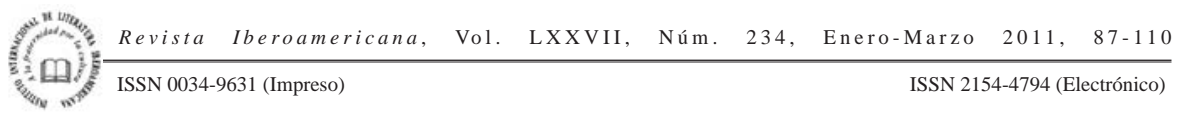


En cuanto a la acusación de racismo en Maitena, el mismo Fernández L’Hoeste la matiza indicando que "como en la mayoría de las sociedades de Occidente, la experiencia del racismo en el mundo de Maitena es de índole estructural... [L]o único que le cae en culpa al mundo argentino de Maitena es la reproducción de una serie de convenciones sociales con un elevado grado de exactitud... Hasta cierto punto, lo que hace Maitena es mostrar las cosas tal y como son” (“Más allá” 16). No obstante, Fernández L’Hoeste no repara en una de las tiras de Maitena, "Manual del perfecto racista," donde la humorista argentina clara y contundentemente critica y explica el tipo de racismo que circula en la sociedad occidental actual, especialmente en la clase media-alta (véase fig. 3).

En este punto, creo que es importante enfatizar que Maitena era muy consciente en sus principios profesionales (antes del salto a la fama mundial) del público que iba a leer las revistas o periódicos en las que estaba publicando su obra. Sabía que era un público burgués, conservador. Esta conciencia la lleva a reírse a veces de ese público (aunque ella misma provenga de esa misma clase social) y a retratar de manera crítica sus vicios. Por eso, conscientemente, en ocasiones introduce temas controvertidos y supuestamente prohibidos en esas publicaciones:

me encantan los lectores que me escriben para putearme. Porque el humor tienequemolestarun poco. No quiero que la gente que a míme parece una mierda esté de acuerdo conmigo. Me gusta mucho desde La Nación [un periódico conservador] decir que hay lesbianas, gays, que la gente tienen amantes, que se divorcia, que a veces no quiere a sus padres. Tiene gracia ponerlo ahí. Si escribieran en Página 12 [una publicación progresista] estarían todos de acuerdo y no serviría para nada. (Malamud 26)

En cuanto a la crítica de que el mundo que Maitena representa

Fig. 3. Maitena Burundarena. "Manual del racista perfecto". Todas las mujeres alteradas. $2^{\mathrm{a}}$ ed (Barcelona: DeBolsillo/Random House Mondadori, 2007; 235).
Manual del racista perfecto

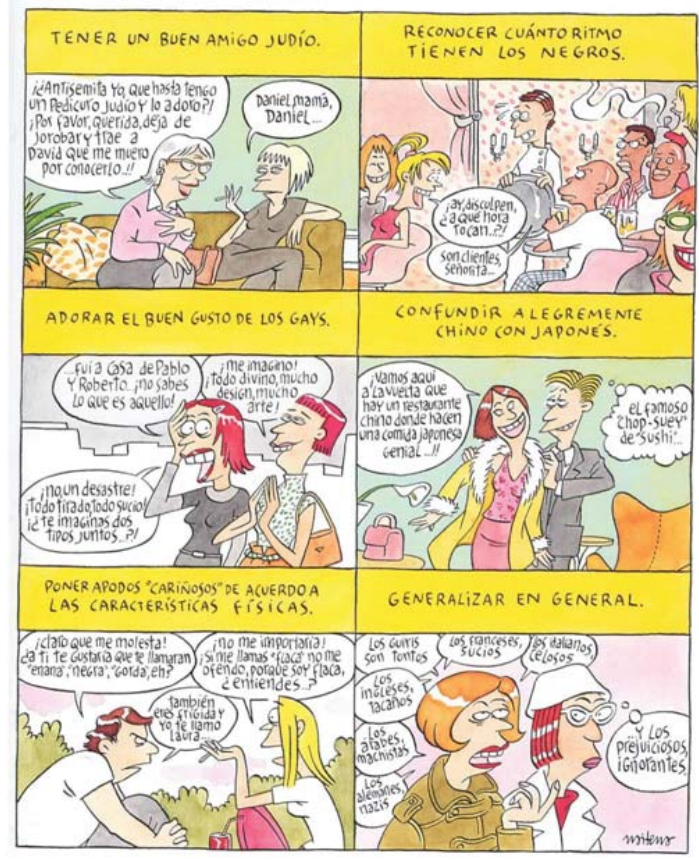

\footnotetext{
ISSN 0034-9631 (Impreso)
} 
Seis buenas razones para ser una mujer frívola

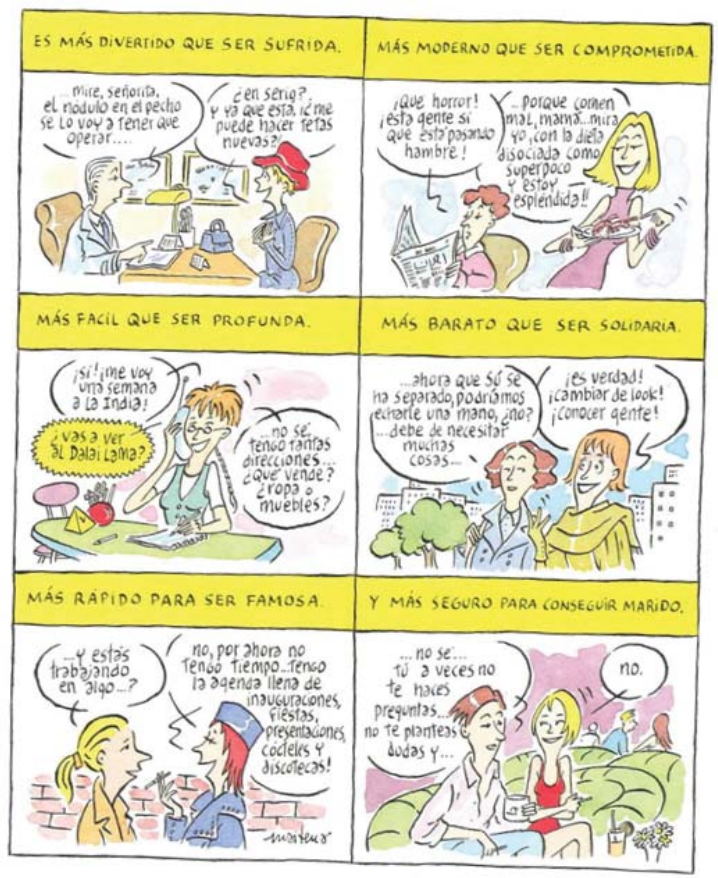

Fig. 4. Maitena Burundarena. "Seis buenas razones para ser una mujer frívola". Todas las mujeres alteradas. $2^{2}$ ed. (Barcelona: DeBolsillo/Random House Mondadori, 2007, 95). es exclusivamente el de la clase media-alta rioplatense (Fernández L’Horeste, “Más allá” 15), aunque esto sea cierto, lo único que demuestra es, como acabo de indicar, que Maitena es muy consciente de para qué público escribe en cada momento. Así, como explica Dillon, a pesar de que la revista Para ti la contrata por primera vez,

justo en el momento en que su estilo punk era más crudo, ... la revista "femenina" por excelencia tuvo la gracia de buscar en la mirada de una "otra” [la Maitena punk] lo que podría haber en común con las mujeres que la leían en las peluquerías; y sobre todo las que la compran por las dietas que cíclicamente aparecen y que -en secreto- los editores aseguran que levantan las ventas cuando parece que pueden caerse. (par. 25)

Dillon nos recuerda aquí que Maitena no sólo escribe para un público burgués y no sólo es a éste al que le interesa escandalizar. Es preciso recordar sus orígenes como dibujante punk de cómics eróticos, puesto que en este contexto marginal Maitena también era consciente de los prejuicios a los que se enfrentaba dentro de las coordenadas particulares del cómic erótico heterosexista y buscó formas de subvertir el discurso dominante. Así, Maitena indica que

[c]uando hacía comics [sic] eróticos, en Sex Humor, también tomaba personajes femeninos. Y tenía mis pequeñas revanchas, como con La Fiera, que era una mujer que tenía del sexo una utilización muy masculina. Me divertía, porque era una redacción con mucho olor a huevo, muy machista, que estaban todo el tiempo con la muñeca inflable en la cabeza y en donde yo era la única mujer. A mis compañeros les molestaba La Fiera, los re-molestaba porque hacía lo mismo que ellos, se comía los tipos y los escupía después como a carozos. (Dillon par. 26)

Revista Iberoamericana, Vol. LXXVII, Núm. 234, Enero-Marzo 2011, $87-110$
ISSN 2154-4794 (Electrónico) 
Es decir, Maitena ya ponía de manifiesto y ridiculizaba en ese contexto el doble patrón de comportamiento al que se somete a las mujeres. Siempre ha tenido un propósito revulsivo, crítico que la vuelve a entroncar con el grotesco criollo y el costumbrismo mencionados por Tompkins y De Santis, por un lado, pero con la crítica feminista de Bretécher y Bechdel, por el otro.

Más aún, es crucial separar los personajes que Maitena representa en sus tiras -es decir, poniendo en su boca las preocupaciones de ciertas clases de mujeres de clase media-alta-de los logros y opiniones de la Maitena real, la artista y profesional. Como ella misma ha indicado a menudo en sus entrevistas, "mi trabajo no es autorreferencial" (Krmpotic 77). Por ejemplo, Maitena es consciente de que en sus historietas representa una diversidad de experiencias femeninas y a menudo es tremendamente crítica con ciertos comportamientos estereotipados a los que se

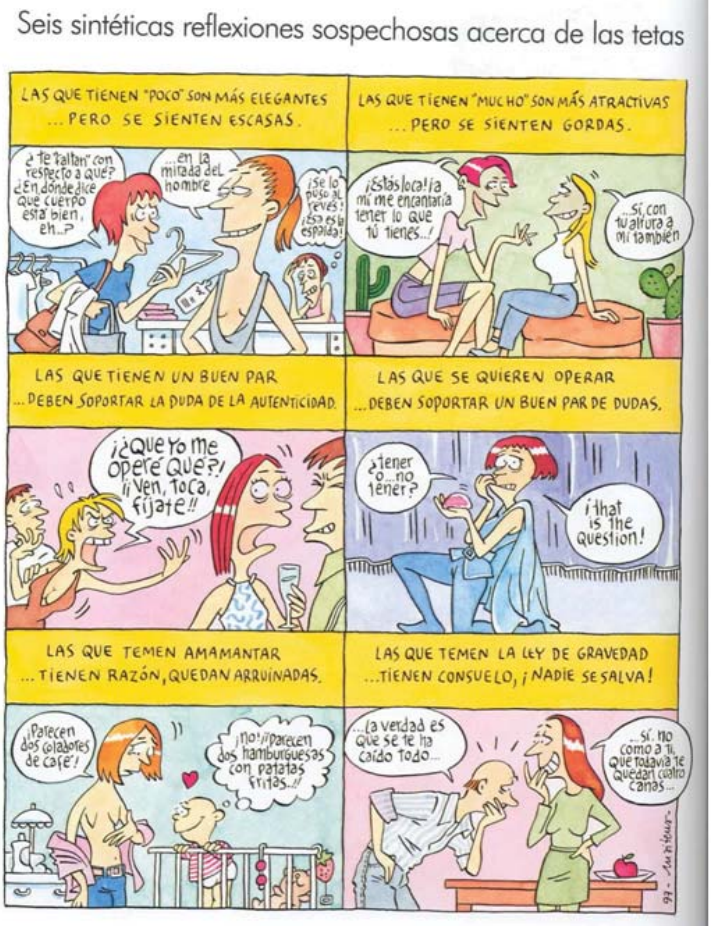

Fig. 5. Maitena Burundarena. "Seis sintéticas reflexiones sospechosas acerca de las tetas". Todas las mujeres alteradas. $2^{\mathrm{a}}$ ed. (Barcelona: DeBolsillo/Random House Mondadori, 2007; 270). ven avocadas, si quieren sobrevivir, algunas amas de casa de la clase media-alta que dependen económicamente de sus maridos. Una lectura entre líneas y a contra-pelo (el tipo de lectura que Josefina Ludmer reclamaba como necesaria para descodificar las "tretas del débil” que las escritoras latinoamericanas desde Sor Juana han tenido que blandir contra un sistema sexista) nos permite distinguir la manera en que Maitena sugiere que la mujer necesita la independencia económica o, de lo contrario, no le queda más remedio que actuar de una forma estereotípica para poder salir adelante. ${ }^{12}$ En la historieta "Seis buenas razones para

${ }_{12}$ Siguiendo presupuestos del feminismo liberal típico de Virginia Woolf, Maitena aboga por la necesidad de que las mujeres adquieran la independencia económica:

ISSN 0034-9631 (Impreso) 
ser una mujer frívola” (fig. 4), por ejemplo, Maitena critica la frivolidad en la mujer con privilegios de clase pero en la viñeta final demuestra que dicho comportamiento es el único que le queda a este tipo de mujer en particular para poder atraer a un hombre, puesto que los hombres que están disponibles (supuestamente en el contexto de la clase media-alta

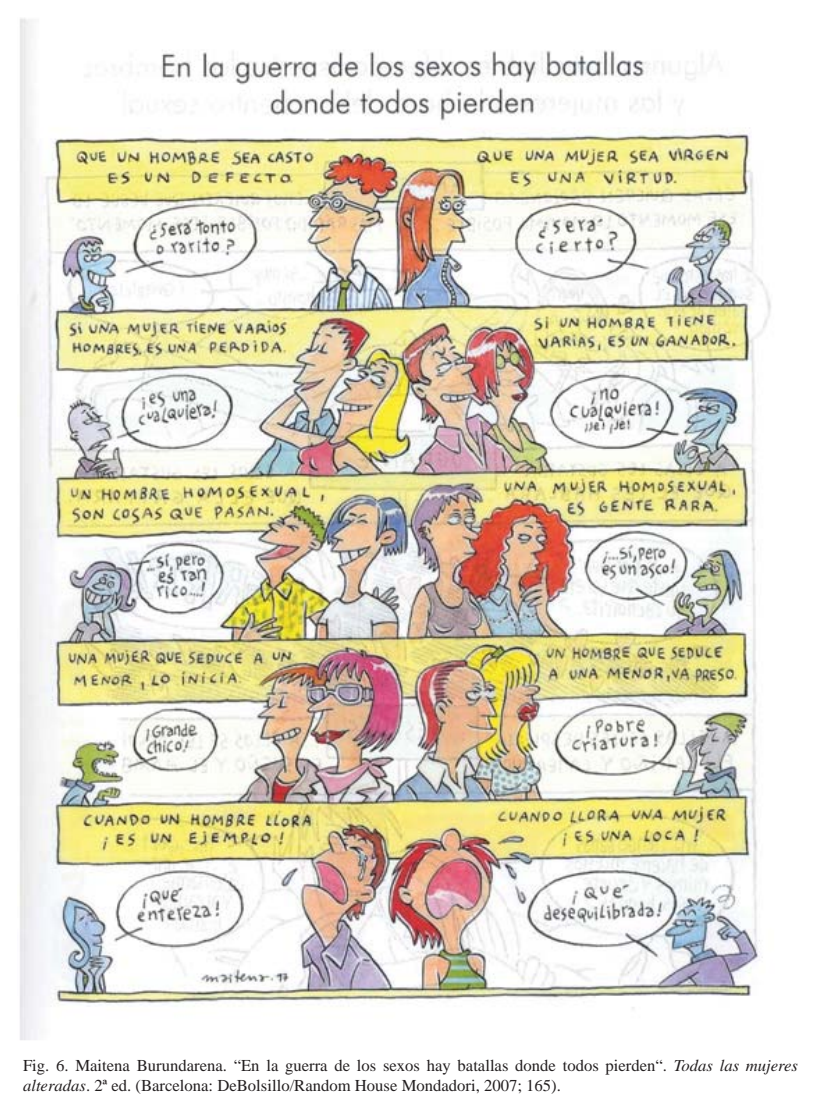
rioplatense) prefieren tener a su lado una mujer que no piense por sí sola ni rete las opiniones de su marido. Otros comportamientos estereotípicos que Maitena somete a escarnio al mismo tiempo que los comprende y les presta un espacio representacional incluyen también la preocupación por el aspecto físico y por seguir siendo deseada por los hombres (véase fig. 5). Sinembargo,nuncapierdela ocasión de apuntar el doble patrón de comportamiento al que se ven sometidas las mujeres en una sociedad heterosexista (véase fig. 6).

La otra línea crítica de acercamiento a la obra de Maitena es la más matizada y detallada representada por Tompkins quien, en su ensayo rigurosamente documentado "Las Mujeres alteradas y Superadas

ESTHER: ¿Crees que a tu madre y a muchas mujeres de su generación las ha perjudicado no ser independientes económicamente?

MAITENA: Muchísimo. A mí me parece tan fundamental que nunca en la vida pasé un minuto en otra situación. Lo primero que tiene que ser una mujer es independiente económicamente. Pero no de su marido, de quién sea.

Además a mí me gusta la gente que trabaja, que se gana su dinero. Siempre me gustó. No lo puedo evitar. (Tusquets 71).

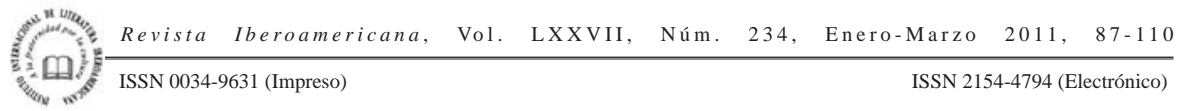


de Maitena Burundarena: Feminismo 'Made in Argentina,'” arguye que la obra de Maitena sí es feminista, pero que debe entenderse de qué tipo de feminismo se trata en el contexto de las particularidades de la historia de dicho movimiento en la Argentina. Específicamente, Tompkins indica que:

El feminismo de Maitena se desprende de los siguientes temas recurrentes: 1) crítica implícita a la supuesta evolución de la condición de la mujer; 2) dudas; 3) propuestas feministas; 4) double standard y 5) actitudes típicas: en relaciones heterosexuales y entre amigas, homofobia, relaciones con hombres "gay”, actitudes ante lesbianas, travestis, el psicoanálisis, la realidad virtual y la cirugía estética. (42)

Acertadamente, Tompkins localiza algunos de los puntos de vista representados en las tiras de Maitena dentro de las premisas del feminismo liberal (50). Pero también subraya la ambivalencia de Maitena ante el feminismo radical y otros feminismos:

Desde una posición postfeminista, Maitena presenta una crítica implícita a los supuestos logros del feminismo liberal. Asimismo, y en antítesis del feminismo radical tal y como lo demuestra el escueto interés en las relaciones lésbicas, se encuentra el tema recurrente de las relaciones heterosexuales, la legendaria "batalla de los sexos.” Finalmente, se presenta un feminismo anclado en el cuerpo, pero a diferencia tanto de la vertiente (puritánica) angloeuropea como de la escritura con el cuerpo de la tradición francesa, las ilustraciones gráficas de Maitena proponen cuerpos espléndidos, sin que obste el que estén esculpidos por la cirugía. Es decir que al analizar la producción gráfica de Maitena no habría que llegar a la conclusión de que su actitud es poco progresiva, sino más bien que su paradójicamente vitriólica pero compasiva mirada logra plasmar la variedad de posturas feministas de las mujeres argentinas. (57)

Estoy de acuerdo con Tompkins en la mayoría de sus argumentos, pero creo que merece la pena detenerse un momento en su velada recriminación sobre la falta de representaciones de lesbianas en el conjunto de la obra de Maitena (22), especialmente si se tiene en cuenta que sí proliferan las representaciones de hombres gay y de transgéneros MTF (de hombre a mujer).

En varias entrevistas, le han preguntado a Maitena por qué no hace humorismo político (entendiendo por éste la crítica directa a eventos históricos y políticos de interés nacional e internacional). La respuesta que siempre da la humorista es la siguiente:

Cuando vivís en Latinoamérica, vivís muy cerca de las injusticias sociales, de la marginación, de la miseria. Entonces cobra otro sentido la política. Y a mí no me hacen gracia las burradas de los políticos. A veces me preguntan si haría humor político. No, porque no me puedo reír de una burrada, cuando sé que detrás de la burrada, detrás de robos y de corrupción, hay gente que se muere de hambre de verdad. Me indigna, y no

Revista Iberoamericana, Vol. LXXVII, Núm. 234, Enero-Marzo 2011, $87-110$
ISSN 0034-9631 (Impreso) 
veo modo de encontrarle la vuelta, de poder hacer con esto humor. (Tusquets 74-75)

El que a Maitena le parezca imposible sacarle la punta humorística a una situación política seria, me lleva a considerar la ausencia de chistes sobre lesbianas en su obra desde una perspectiva diferente a la de Tompkins. Y merece la pena, en este contexto, mencionar que Maitena es bisexual y que tuvo una relación muy apasionada con una mujer durante tres años. Esto es importante, porque, como ella misma indica, durante esa relación se dio cuenta:

de que hay un prejuicio sobre la homosexualidad... [S]ocialmente está mucho más aceptada la homosexualidad masculina. Está lleno de hombres gays que dicen que son gays, y hasta personas como mi mamá pueden entender que un hombre sea gay y buena persona y talentoso. En cambio, hay algo con la homosexualidad femenina muy jodido socialmente. Por eso muchas mujeres no lo dicen tan abiertamente como los hombres. Se ven muchos más homosexuales hombres que mujeres, y no creo que sea porque haya muchos más. Cuando una lesbiana tiene una cosa muy masculina, causa rechazo, en los hombres y en muchas mujeres. En cambio, un homosexual afeminado, no. La gente lo ve como algo simpático. (Tusquets 38, 74)

Esta conciencia del doble patrón evaluativo al que se ven sometidas las lesbianas, queda patente en la tercera viñeta de la historieta "En la guerra de los sexos hay batallas donde todos pierden” (fig. 6). Me parece defendible argumentar que Maitena ha dibujado pocos

chistes sobre lesbianas en sus historietas

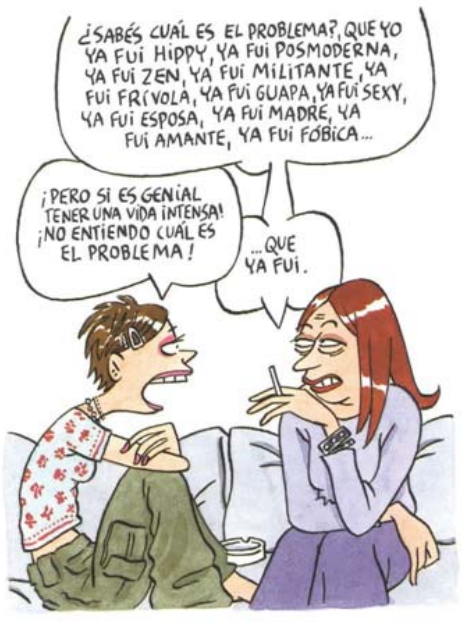
porque considera que los prejuicios y la discriminación a los que se las somete son demasiado serios como para burlarse de ellos, especialmente porque ella misma los ha sufrido en su carne. Por tanto, el impacto subversivo de Maitena hay que buscarlo a menudo en lo que no dice y el porqué no lo dice.

En cuanto a la reinscripción de ciertos estereotipos machistas sobre la mujer, creo que una breve comparación con la serie norteamericana Dykes to Watch Out For (DTWOF) deAlison Bechdel, nos ayudaráa entender lo que Maitena propone al blandir dichos estereotipos. Aunque Bechdel tiene todo tipo de lectores, incluso hombres Fig. 7 Maitena Burundarena. Sin título. Todas las superadas. (Barcelona: Lumen, heterosexuales progresistas, sus tiras $2007 ; 19)$.

\footnotetext{
Revista Iberoamericana, Vol. LXXVII, Núm. 234, Enero-Marzo 2011, $87-110$
ISSN 2154-4794 (Electrónico)
} 
cómicas están claramente destinadas a un segmento específico y pequeño de la población: mujeres “queer” (bisexuales, lesbianas, transgénero FTM de mujer a hombre- y heterosexuales que se salen de la norma dominante de comportamiento), progresistas, con estudios, y de clase media, la mayoría de las cuales viven en Nueva Inglaterra u otros estados progresistas de los EE.UU. La conciencia de narrar para este público específico le ayuda a jugar con ciertos estereotipos sobre las lesbianas (empezando con el mismo título de la serie, que hace uso de un término ya resemantizado pero originalmente derogatorio: “dykes” o "bollera," en castellano). Mientras que

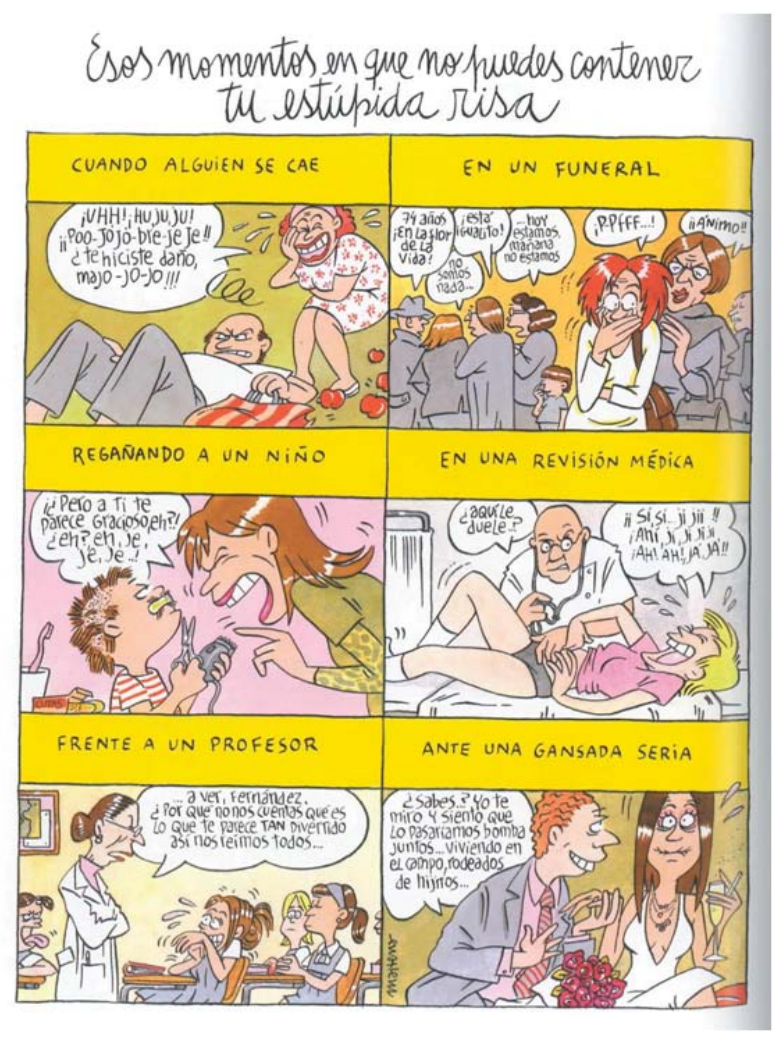

Fig. 8. Maitena Burundarena. "Esos momentos en que no puedes contener tu estúpida risa". Todas las mujeres alteradas. $2^{\mathrm{a}}$ ed. (Barcelona: DeBolsillo/Random House Mondadori, 2007; 320). ciertas ideas o imágenes usadas por Bechdel pudieran reforzar estereotipos negativos de la comunidad lesbiana para un público que se sitúe fuera de dicha comunidad, para el público lector al que está dirigida la serie queda claro que estos estereotipos se presentan en clave de parodia, ironía y humor. Al mismo tiempo, al multiplicar Bechdel las representaciones de lesbianas (véase por ejemplo su alfabeto de lesbianas intercalado en el no. 1 de DTWOF), atestigua la complejidad de esta comunidad y reclama un espacio de representación dentro de la narrativa gráfica para registrar las preocupaciones y dificultades a las que se enfrentan sus “bolleras.” Dicho de otra manera, aunque cualquiera puede leer las tiras cómicas tanto de Bechdel como de Maitena y puede contribuir con su lectura a crear un significado particular, cuando las historietas destinadas a un grupo específico de lectores (comunidades “queer” liberales y radicales, de clase media de EE.UU. en el caso de Bechdel; mujeres

Revista Iberoamericana, Vol. LXXVII, Núm. 234, Enero-Marzo 2011, $87-110$
ISSN 2154-4794 (Electrónico) 


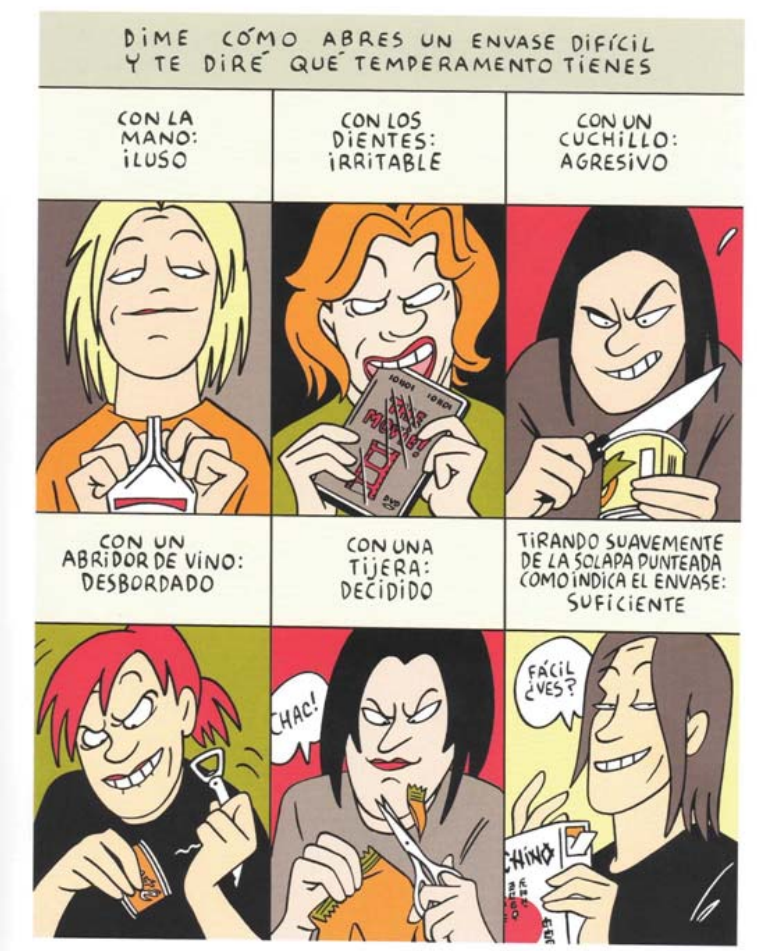

Fig. 9. Maitena Burundarena. "Dime cómo abres un envase difícil y te diré qué temperamento tienes". Curvas peligrosas 2. (Barcelona: Lumen, 2005; 9). heterosexuales blancas de la clase media-alta en Latinoamérica y Europa en el caso de Maitena) este grupo-objetivo (ingroup o target group), diría yo, consume dichos estereotipos desde una perspectiva auto-crítica y es consciente de la carga de parodia quellevan. Ellector ideal, entonces, se torna en lo que en un contexto literario yo he calificado como "lector entendido" (Pérez-Sánchez 36-38). En otras palabras, entre el público al que prefiere dirigirse la humorista, hay un entendimiento de la labor paródico-crítica que la artista está queriendo realizar por medio de estos estereotipos y del tipo de subversión del discurso dominante que moviliza. Se intercambia entre autora y lectoras un guiño de complicidad. En el caso específico de Maitena, creo que simultáneamente apunta a los estereotipos de género impuestos en las mujeres y los hombres y también indica maneras en las que las mujeres pueden usar performativamente (en el sentido usado por Judith Butler) dichos estereotipos para reírse de ellos y desmantelarlos. Por ejemplo, en el chiste de la fig. 7, una mujer rondando los cincuenta, hablando con una mujer veinteañera, posiblemente su hija, indica: “¿Sabes cuál es el problema?, que yo ya fui hippy, ya fui posmoderna, ya fui zen, ya fui militante, ya fui frívola, ya fui guapa, ya fui sexy, ya fui esposa, ya fui madre, ya fui amante, ya fui fóbica....” La joven le contesta: “¡Pero si es genial tener una vida intensa! ¡No entiendo cuál es el problema!” a lo que la mujer madura tajantemente replica: “...Que ya fui”. En esta viñeta, Maitena al mismo tiempo que parodia todas las modas de identidad y de auto-descubrimiento por las que han pasado las mujeres blancas occidentales de clase media-alta desde los años 60 , también se burla y critica el que estas mujeres, al 
fin y al cabo, sigan viéndose avocadas a ser desvaloradas una vez alcanzan una cierta edad. Es decir, nos está criticando la discriminación sexista hacia las mujeres maduras. El código gráfico del chiste es especialmente importante, puesto que la manera de vestir de ambas mujeres nos revela el contraste generacional. Asimismo, la expresión de estar ya de vuelta de todo de la mujer madura, quien mira con exasperación a la joven, también sugiere su conciencia de que gracias a que ella haya experimentado y abierto tantas brechas (como hippy, como posmoderna, etc.) es lo que le permite a la joven tener acceso a sus libertades actuales. Ala vez, la reacción de la joven apunta al hecho de que su generación ha recibido ya todo mascado y digerido, no ha luchado, no ha experimentado y, por tanto, ha vivido una vida menos intensa, sobre-protegida. Y sin embargo, hay camaradería entre ambas mujeres de dos generaciones dispares.

Esta estrategia de simultáneamente jugar con estereotipos pero desmantelarlos, junto a la

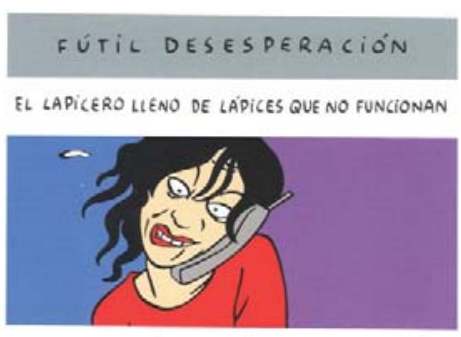

TENER MIL DISCOSY NINGUNO PARA PONER

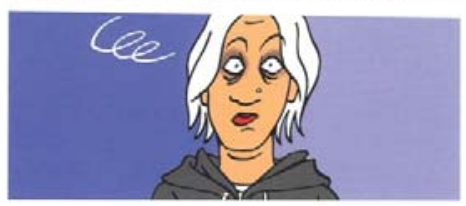

BUSLAR LAS GAFAS SIN TENERLAS PUESTAS

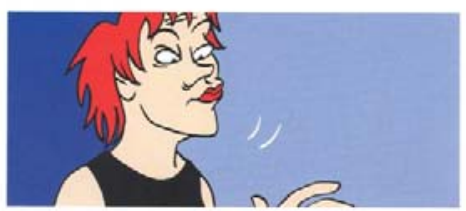

Fig. 10. Maitena Burundarena. "Fútil desesperación”. Curvas peligrosas 2. (Barcelona: Lumen, 2005; 56). multiplicidad de representaciones de mujeres de varias generaciones en la obra de Maitena explica, tal vez, la respuesta que, según Fernández L'Hoeste, sus estudiantes Latinas de los EE.UU. tiene hacia la obra de Maitena:

The most disconcerting thing of all is that, when I used Maitena as a text in a graduate seminar, despite the evidence available, most of my students, who happen to be women, celebrated her comics profusely. They were conscious of how class and race were discarded in favor of gender, yet they argued that Maitena's views were welcome and valid, excusing, to a certain extent, alternate prejudice... Comics do not pretend to be a politically correct medium, so I guess these attitudes are comprehensible. Yet, in a naïve way, what I find disenchanting is the awareness of the lack of problematization and the disregard for a critical engagement of identity, contemplating all forms of capital, in the path to mindful entertainment. Ultimately, one could argue that Maitena uses parody in the way of a soap opera, as a means to poke fun at the lifestyle of a privileged sector in Latin America. Regardless of this viewpoint, what remains indisputable is that, as a cartoonist in an enviable position (given her sales volume and social stature), she has not developed a suitable narrative mechanism to explore and problematize the aspects questions in this critique. ("Beyond Just Gender" 360)

Revista Iberoamericana, Vol. LXXVII, Núm. 234, Enero-Marzo 2011, $87-110$
ISSN 2154-4794 (Electrónico) 


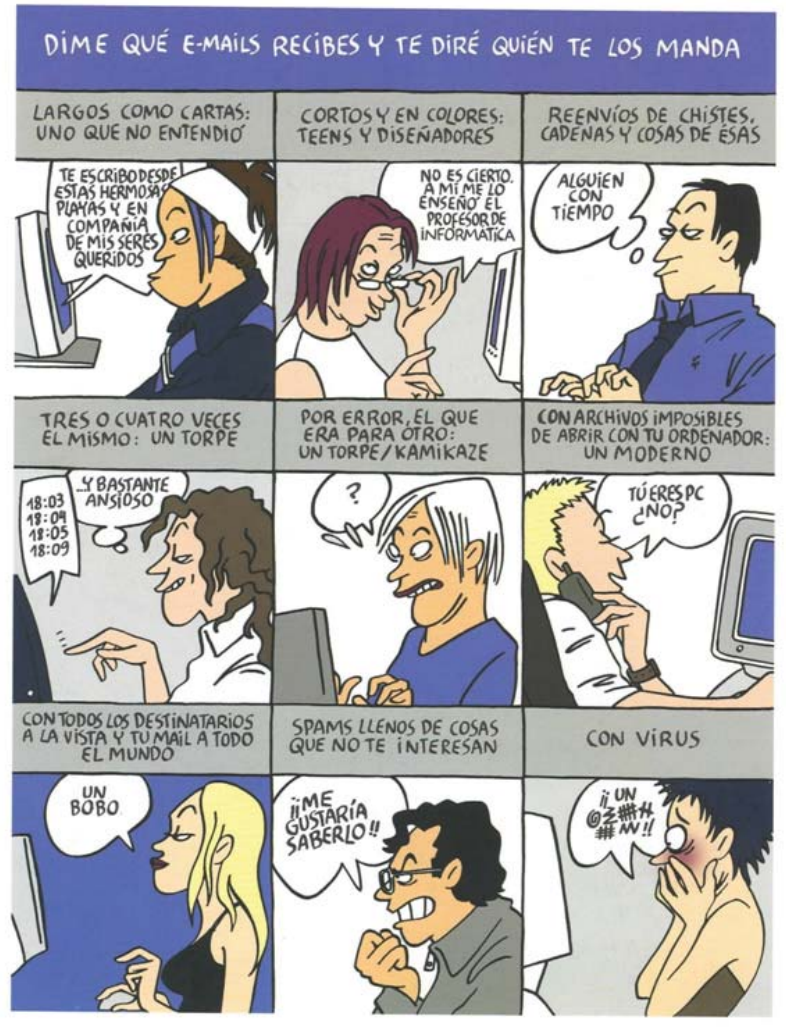

Fig. 11. Maitena Burundarena. "Dime qué e-mails recibes y te diré quién te los manda”. Curvas peligrosas. $4^{\mathrm{a}}$ ed. (Barcelona: lumen, 2006; print; 14).
Además de lo que ya he argumentado hasta el momento para contrarrestar la visión restrictiva que Fernández L'Hoeste's tiene del proyecto político de Maitenaydelasrespuestas de sus lectoras-objetivo, creo que hay incluso otras maneras en las que Maitena representa un paso adelante en la transmisióndeunmensaje político subversivo particularmente si la comparamos con las dibujantes españolas a las que me he referido antes: (1) Maitena presenta a la mujer no ya como secundaria al hombre, sinocomolarepresentante del sujeto universal en sustitución del hombre como tal. Es decir, Maitena cada vez con más frecuencia abandona la representación de situaciones específicamente genérico-sexuales para presentar, en vez, cosas que le podrían pasar a cualquiera. Mientras que la tendencia en estos casos sería usar a hombres como representantes de esas experiencias supuestamente universales, Maitena a menudo usa a las mujeres, o una combinación de mujeres y hombres, convirtiéndolas, por tanto, en sujeto universal (véanse figs. 8, 9, 10 y 11). Este desplazamiento del hombre como único sujeto representativo de lo universal-gesto que, dicho sea de paso, Maitena realiza casualmente y sin llamar la atención sobre el mismo- es en sí, un acto sugestivamente radical y subversivo. (2) Hay una diferencia entre las posturas políticas de Maitena como autora y las de sus personajes. Mientras que algunos de éstos transmiten ideas reaccionarias, Maitena misma es marcadamente progresista y ha conseguido transmitir 
estas ideas progresistas sin sacrificar su éxito profesional y sin rendirse a las exigencias machistas del mercado editorial, como ha tenido que hacer Ana Miralles (Pérez-Sánchez 171); es capaz de trasmitir mensajes feministas y de apoyo a las lesbianas sin tener que pasarse al medio puramente verbal, como no le quedó más remedio a Asun Balzola (Pérez-Sánchez 171) y no ha evitado reflejar directamente el compromiso político pasándose al medio puramente visual y abandonando el código verbal de su narrativa gráfica, como hiciera Ana Juan (Pérez-Sánchez 171), comprometiéndose así, de lleno, con un medio-el arte secuencial (término acuñado por Will Eisner)-que se ha convertido en uno de los más complejos medios de expresión artística, cultural y política de la modernidad de principios del milenio. En resumen, Maitena ha logrado controlar las riendas de las presiones y oportunidades que el mercado capitalista le ofrece para poder presentar una gran variedad de puntos de vista feministas que encuentran sus ecos en contextos artísticos y culturales simultáneamente locales (Argentina) y globales, como lo demuestra su éxito de ventas en todo el mundo.

\section{Obras Citadas}

Abreu Vivas, Michele. “'Literatura Mulherzinha’: a construção de feminilidades nas tirinhas da série Mulheres Alteradas de Maitena”. Tesis de maestría. Pontificia Universidade Católica do Rio de Janeiro, 2005. OCLC FirstSearch. 1 feb. 2009.

Bechdel, Alison. Dykes to Watch Out for: Great Romances that Never Were. Ithaca: Firebrand Books, 1986.

Fun Home: A Family Tragicomic. New York: Houghton Mifflin, 2006.

Burundarena, Maitena. "Biografía: Nunca estuve en la luna”. Maitena, Página Oficial. N.p., 2003. Web. 2 mar. 2009. Curvas peligrosas. $4^{\mathrm{a}}$ ed. Barcelona: Lumen, 2006. Curvas peligrosas 2. Barcelona: Lumen, 2005.

Todas las mujeres alteradas. $2^{\mathrm{a}}$ ed. Barcelona: DeBolsillo/Random House Mondadori, 2007. Todas las superadas. Barcelona: Lumen, 2007.

Cipolloni, Marco. "Eva, Maitena e le altre... Ovvero le donne espagnole tradotte tradite dal femminismo”. Spagna Contemporanea 27 (2005): 157-62.

Coma, Javier. "En manos femeninas”. Cómics: Clásicos y modernos. Ed. El País. Madrid: Promotora de Informaciones, 1988. 321-36.

De Santis, Pablo. “Sobre la condición femenina”. Suplemento cultural, La Nación (16 ene. 2002). 1 jul. 2009.

Dillon, Marta. “Estados (no tan) alterados: Entrevista a Maitena”. Página 12, Suplemento Las12 (16 dic. 2005). 24 jun. 2009.

Eisner, Will. Comics as Sequential Art [1985]. Tamarac: Poorhouse Press, 1996.

Revista Iberoamericana, Vol. LXXVII, Núm. 234, Enero-Marzo 2011, $87-110$
ISSN 0034-9631 (Impreso) 
Fernández L'Hoeste, Héctor D. "Beyond Just Gender: On The World of Maitena Burundarena”. International Journal of Comic Art (primavera 2006): 346-61.

"Más allá del género: acerca del mundo de Maitena Burundarena". Cenizas: Revista narrativa/gráfica 0 (mar. 2006): 14-20.

Ferreira Dantas, Daiany. “Sexo, Mentiras e HG: Representação e auto-representação das mulheres nos quadrinhos”. Tesis de maestría. Universidade Federal de Pernambuco, 2006. OCLC FirstSearch. 1 feb. 2009.

Gallo, Miguel Ángel. Los comics: un enfoque sociológico. México: Quinto Sol, 1980. Krmpotic, Milo J. “Maitena”. Qué Leer 59 (2001): 76-77.

Ludmer, Josefina. "Las tretas del débil”. La sartén por el mango.Patricia Elena González y Eliana Ortega, eds. Río Piedras: Huracán, 1985. 47-54.

Malamud, Luciana. "Maitena: Una madre de curvas peligrosas”. Lateral 12(2005): 24-27.

Marika [Mari Carmen Vila]. “Un silencio”. Cómics: Clásicos y modernos. Ed. El País. Madrid: Promotora de Informaciones, 1988. 323.

Merino, Ana. El cómic hispánico. Madrid: Cátedra, 2003.

“Maitena y las transformaciones de las mujeres”. Leer 23/188 (dic.-ene. 2007): 178-79.

Moreno, María. Vida de vivos: Conversaciones incidentales y retratos sin retocar. Buenos Aires: Sudamericana, 2005. 242-51.

Pérez-Sánchez, Gema. Queer Transitions in Contemprary Spanish Culture: From Franco to 'la movida'. Albany: SUNY P, 2007.

Rohter, Larry. “A Sassy Appraisal of the Sexes”. The New York Times (23 mar. 2004). 24 jun. 2009.

Tompkins, Cynthia. "Las Mujeres alteradas y Superadas de Maitena Burundarena: Feminismo 'Made in Argentina”'. Studies in Latin American Popular Culture 22 (2003): 35-60.

Tusquets, Esther. Maitena. Barcelona: RqueR, 2005.

Revista Iberoamericana, Vol. LXXVII, Núm. 234, Enero-Marzo 2011, 87-110
ISSN 2154-4794 (Electrónico) 